\title{
Is Insomnia an Independent Predictor of Obstructive Sleep Apnea?
}

\author{
Robert N. Glidewell, PsyD, Emily K. Roby, PsyD, and William C. Orr, PhD
}

Introduction: Obstructive sleep apnea (OSA) is a disorder with high prevalence in primary care. However, little research exists on screening for OSA in primary care samples.

Methods: One hundred family medicine patients completed standardized symptom and demographic questionnaires and a structured clinical interview for sleep disorders. Two-step logistic regression was performed to determine the independent predictive value of insomnia for clinical identification of OSA. Additional $t$ tests were computed to examine age and sex patterns of insomnia.

Results: A model including body mass index and daytime sleepiness predicted OSA status $\left(\chi^{2}=\right.$ $18.63 ; P<.001)$ and explained $27 \%$ of the variance in $0 S A$ clinical diagnosis. Addition of insomnia scores to the model significantly improved predictive utility $\left(\chi^{2}=25.79 ; P<.001\right)$ and explained $36 \%$ of the variance in OSA. Insomnia scores were higher for women compared with men $(P=.033)$ and women with OSA compared with women without OSA $(P=.007)$.

Conclusions: Inquiry regarding insomnia may improve clinical identification of OSA when screening for OSA in primary care. This finding possibly is unique to the evaluation of OSA in a primary care versus sleep laboratory sample. The predictive utility of insomnia may be specific to women. $(\mathrm{J}$ Am Board Fam Med 2012;25:104-110.)

Keywords: Family Medicine, Insomnia, Obstructive Sleep Apnea, Primary Health Care

Obstructive sleep apnea (OSA) is a sleep-related breathing disorder estimated to occur in $2 \%$ of women and $4 \%$ of men in the general adult population. ${ }^{1}$ Though more than $30 \%$ of patients presenting at primary care clinics are at high risk for OSA, many remain undiagnosed and untreated. ${ }^{2}$ Untreated OSA is associated with increased medical and psychiatric morbidity and increased mortality. ${ }^{3-10}$ Diagnosis of OSA requires costly and cumbersome procedures including overnight poly-

This article was externally peer reviewed.

Submitted 14 April 2011; revised 4 August 2011; accepted 15 August 2011.

From the Lynn Institute for Healthcare Research, Colorado Springs, CO (RNG, ER, WCO) and Oklahoma City, OK (WCO)

Funding: All financial support was provided by the Lynn Institute for Healthcare Research.

Conflict of interest: none declared.

Disclaimer: The Lynn Institute had no involvement in the study design; collection, analysis, or interpretation of data; writing of the manuscript; or decision to submit for publication.

Corresponding author: Robert N. Glidewell, PsyD, Lynn Institute for Healthcare Research, 1625 Medical Center Point, Suite 260, Colorado Springs CO 80907 (E-mail: rglidewell@lhsi.net). somnography (PSG) or portable monitoring of nocturnal respiration and oxygen saturation. ${ }^{11-13}$ These factors make accurate identification of OSA patients in the primary care setting critically important for health risk reduction, health promotion, health care cost management, and patient care.

Numerous investigations have found patient self-report of various signs, symptoms, risk factors, and physiologic variables (eg, snoring, daytime sleepiness, obesity) as a useful method for clinical screening of OSA and prioritization of patients for PSG. ${ }^{14-18}$ The predictive characteristics of specific screening questionnaires and prediction models have been published and several reviews exist. ${ }^{19-21}$

However, existing models have 3 limitations that need to be overcome to optimize clinical identification of OSA in the primary care setting. First, with the exception of the Berlin and OSA 50 questionnaires, previous investigations have used samples recruited from sleep centers and were composed of subjects who already were prescreened and referred for evaluation of suspected sleep apnea or a general sleep complaint. ${ }^{17,18,22-28}$ As noted by 
Maislin and colleagues, ${ }^{18}$ because of differences in both the incidence of disease and the distribution of clinical characteristics, the predictive characteristics of diagnostic tests may vary considerably from one clinical population to another. Accordingly, we cannot assume that the utility of previously researched prediction models is maintained when applied to a primary care population.

Second, previous models, including the Berlin and OSA 50 questionnaires, are inconsistent with current knowledge regarding the epidemiology and clinical presentation of OSA. Although many previously published prediction models utilize both sex and body mass index (BMI), recent findings of Tishler and colleagues ${ }^{29}$ suggest that sex becomes an unreliable predictor of OSA after age 50 and BMI becomes an unreliable predictor of OSA after the age of 60 . In addition, a subpopulation of OSA patients with normal BMI exists. ${ }^{30}$ Thus, use of $\mathrm{BMI}$ in the initial screening will bias against identification of nonobese OSA patients. Use of sex introduces a similar bias. ${ }^{17,26,31-33}$ There also are clear differences in the clinical presentation and symptom reports between male and female OSA patients. For example, compared with men, women with a diagnosis of OSA or upper airway resistance syndrome are more likely to describe their main sleep problem as insomnia. ${ }^{34}$ In a study of older adults with a presenting complaint of primary insomnia, OSA was identified with PSG in $43 \%$ of subjects despite prescreening for OSA using clinical interview. ${ }^{35}$ Bouscoulet and colleagues ${ }^{36}$ reported that, comparatively, men were more likely to report snoring and daytime napping whereas women were more likely to report insomnia and sedative use.

Finally, although the complaint of insomnia is a known correlate of sleep apnea, it has not been considered a valuable symptom for the clinical prediction of OSA. A recently published clinical guideline for the evaluation of OSA does not recommend insomnia symptoms as part of routine screening for OSA, but instead proposes evaluation of insomnia symptoms only as part of a comprehensive sleep evaluation. ${ }^{11}$ Positive response to a single insomnia question as part of a review of symptoms by primary care physicians has been associated with increased probability of being identified as high risk on the Berlin questionnaire. ${ }^{37}$ Previous prediction models failed to evaluate insomnia symptoms, found insomnia symptoms failed to provide sufficient independent predictive value, or failed to pro- vide sufficient data to allow judgments regarding the specific contribution of insomnia symptoms to the prediction model. ${ }^{14,17,18,22-26,38-40}$

In an effort to overcome these limitations, we completed a study investigating the ability of various clinical variables to improve clinical identification of OSA in a primary care sample. This report presents the results of an exploratory analysis of data obtained from this study. Specific variables analyzed in this report include Insomnia Severity Index (ISI) and Epworth Sleepiness Scale (ESS) scores, age, sex, and BMI.

\section{Methods \\ Procedures}

One hundred patients presenting to a communitybased family medicine clinic were administered the Duke Structured Interview for Sleep Disorders (DSI). The DSI was administered by a clinician (ER) with postdoctoral training in the assessment and treatment of sleep disorders and 10 years of clinical experience. Selection of the interviewer was based on the assumption that a higher level of sleep-specific training and experience would result in more reliable conclusions derived from the DSI. Before completion of the DSI, subjects provided demographic data and completed the ESS and ISI. Subjects were provided a brochure describing the study before seeing their physician, then participation in the study was solicited by their physician at the end of their routine office visit. Recruiting physicians were instructed that all patients were eligible for participation regardless of medical or psychiatric morbidity. Physicians also were instructed that patients with and without sleep complaints were eligible for participation. Subjects were compensated with a $\$ 30$ Visa gift card for participation in the study. This study was approved by the Western Institutional Review Board.

\section{Measures}

The ISI (Table 1) is a 5-item self-report questionnaire that evaluates insomnia symptoms and associated distress and impairment. Items are scored on a 5 -point Likert scale (0 to 4$)$, resulting in a total score of 0 to 28. An individual item response of zero indicates no symptoms, distress, or impairment whereas a response of 4 indicates severe symptoms, distress, or impairment. ${ }^{41}$ The ISI has 
Table 1. Insomnia Severity Index

\begin{tabular}{|c|c|c|c|c|c|}
\hline Questions & & & Rating Categ & fory & \\
\hline $\begin{array}{l}\text { 1. Please rate the current (i.e., last } 2 \\
\text { weeks) severity of your insomnia } \\
\text { problem(s). }\end{array}$ & None & Mild & Moderate & Severe & Very Severe \\
\hline Difficulty falling asleep & 0 & 1 & 2 & 3 & 4 \\
\hline Difficulty staying asleep & 0 & 1 & 2 & 3 & 4 \\
\hline Problem waking up too early & 0 & 1 & 2 & 3 & 4 \\
\hline $\begin{array}{l}\text { 2. How satisfied/dissatisfied are you with } \\
\text { your current sleep pattern? }\end{array}$ & $\begin{array}{c}\text { Very Satisfied } \\
0\end{array}$ & $\begin{array}{c}\text { Satisfied } \\
1\end{array}$ & $\begin{array}{c}\text { Neutral } \\
2\end{array}$ & $\begin{array}{c}\text { Dissatisfied } \\
3\end{array}$ & $\begin{array}{c}\text { Very Dissatisfied } \\
4\end{array}$ \\
\hline $\begin{array}{l}\text { 3. To what extent do you consider your } \\
\text { sleep problem to interfere with your } \\
\text { daily functioning (e.g., daytime } \\
\text { fatigue, ability to function at work/ } \\
\text { daily chores, concentration, memory, } \\
\text { mood, etc.)? }\end{array}$ & $\begin{array}{l}\text { Not At All Interfering } \\
0\end{array}$ & $\begin{array}{c}\text { A Little } \\
1\end{array}$ & $\begin{array}{l}\text { Somewhat } \\
2\end{array}$ & $\begin{array}{r}\text { Much } \\
3\end{array}$ & $\begin{array}{c}\text { Very Much Interfering } \\
4\end{array}$ \\
\hline $\begin{array}{l}\text { 4. How noticeable to others do you think } \\
\text { your sleeping problem is in terms of } \\
\text { impairing the quality of your life? }\end{array}$ & $\begin{array}{c}\text { Not At All Noticeable } \\
0\end{array}$ & $\begin{array}{c}\text { A Little } \\
1\end{array}$ & $\begin{array}{l}\text { Somewhat } \\
2\end{array}$ & $\begin{array}{r}\text { Much } \\
3\end{array}$ & $\begin{array}{c}\text { Very Much Noticeable } \\
4\end{array}$ \\
\hline $\begin{array}{l}\text { 5. How worried/distressed are you about } \\
\text { your current sleep problem? }\end{array}$ & $\begin{array}{l}\text { Not At All Worried } \\
0\end{array}$ & $\begin{array}{c}\text { A Little } \\
1\end{array}$ & $\begin{array}{l}\text { Somewhat } \\
2\end{array}$ & $\begin{array}{r}\text { Much } \\
3\end{array}$ & $\begin{array}{c}\text { Very Much Worried } \\
4\end{array}$ \\
\hline
\end{tabular}

Adapted with permission from Ref. 41 .

been found to be reliable and a valid instrument for evaluation of perceived insomnia severity. ${ }^{42}$

The ESS is an 8-item self-report questionnaire that evaluates the subjective likelihood of dozing in common daily situations. Items are scored on a 4-point Likert scale, with 0 indicating no chance of dozing in a particular situation and 3 indicating a high chance of dozing in a particular situation. Possible scores range from 0 to $24{ }^{43}$

The DSI is a structured clinical interview for the evaluation of the full spectrum of sleep disorders. It produces a positive or negative diagnostic impression for each sleep disorder. It was developed and validated to standardize the screening and selection of subjects with sleep disorders. ${ }^{44}$ The DSI has been validated against the criterion of a sleep disorder diagnosis by clinicians using a combination of PSG plus sleep and medical history. Convergent validity of the DSI for diagnosis of OSA is moderate to high ( $\mathrm{r}=0.45$ to $0.50 ; P=.001)$.

\section{Data Analysis}

Subject characteristics were compared between DSI classified OSA and non-OSA cases using independent samples $t$ tests for continuous variables and $\chi^{2}$ tests with contingency coefficients for cate- gorical variables. Demographic variables included age, BMI, ethnicity, sex, marital status, and employment status. Symptom variables included ESS and ISI total scores.

A 2-step logistic regression then was computed to determine the explanatory value of variables with statistically significant between-group differences. Logistic regression is required in this study because of the use of a categorical dependent variable (ie, OSA vs non-OSA). The Nagelkerke $R^{2}$ statistic was use to report results of the regression. ${ }^{45}$ The regression was completed using only 97 subjects because 3 subjects failed to provide BMI data. Additional $t$ tests were completed to examine the age and sex patterns within the ISI data and between OSA and non-OSA groups. Signs of respiratory obstruction (eg, snoring, witnessed apnea) were not included in this analysis because these symptoms typically are required to trigger suspicion for sleep apnea and our goal here is to identify factors that enhance clinical identification of OSA. Statistical analyses of demographic and symptom characteristics were completed using Statistical Package for the Social Sciences version 15 (IBM, Chicago, IL), whereas logistic regressions were completed using Statistical Package for the Social Sciences version 18. 
Table 2. Demographic and Symptom Characteristics for Obstructive Sleep Apnea (OSA) and Non-OSA Subjects

\begin{tabular}{lcccc}
\hline & OSA $(\mathrm{n}=23)$ & Non-OSA (n $=77)$ & $\chi^{2}$ (Contingency Coefficient) & $P$ \\
\hline Male (\%) & 39 & 46 & $0.287(0.54)$ & .592 \\
Married (\%) & 65 & 58 & $9.60(0.296)$ & .087 \\
White (\%) & 78 & 82 & $1.37(0.116)$ & .849 \\
Employed, full time (\%) & 61 & 52 & $1.20(0.109)$ & .878 \\
\hline & Mean (SD) & Mean (SD) & $t$ & .0 .152 \\
\hline Age & $52.7(13.8)$ & $53.3(16.0)$ & 2.79 & .006 \\
BMI* & $34.9(7.7)$ & $30.2(6.6)$ & 4.55 & .000 \\
ISI total score & $12.0(6.7)$ & $6.4(4.7)$ & 4.12 & .000 \\
ESS total score & $10.9(4.2)$ & $7.2(3.7)$ & & \\
\hline
\end{tabular}

*Body mass index (BMI) statistics are calculated for only 97 subjects ( $\mathrm{n}=22$ OSA; $\mathrm{n}=75$ non-OSA).

ESS, Epworth Sleepiness Scale; ISI, Insomnia Severity Index.

\section{Results}

Demographic and Symptom Characteristics

Demographic statistics are shown in Table 2. No statistically significant between-group differences were observed for sex, ethnicity, age, or employment status. The OSA group had higher mean ISI scores of $12.0 \pm 6.7$, compared with the non-OSA group, who scored $6.4 \pm 4.7(P<.001)$. The OSA group also had higher ESS scores than the nonOSA group $(10.9 \pm 4.2$ vs $7.2 \pm 3.7 ; P<.001)$. $\mathrm{BMI}$ was higher in the OSA group compared with the non-OSA group $(34.9 \pm 7.7$ vs $30.2 \pm 6.6 ; P=$ $.006)$.

\section{Predictive Utility of Insomnia}

A 2-step logistic regression was performed, with the OSA clinical diagnosis (derived from the DSI) as the dependent variable. BMI and ESS total score were included as independent variables in step 1 and ISI total score was added as an additional independent variable in step 2. The results of this regression indicate that step 1 significantly predicted OSA status $\left(\mathrm{df}=2 ; \mathrm{n}=97 ; \chi^{2}=18.63 ; P<\right.$ $.001)$. The $R^{2}$ results indicate that $27 \%$ of the variance in OSA clinical diagnosis is accounted for by step 1 of the model. The results also indicate that addition of ISI scores to the model (step 2) significantly improved the predictive utility of the model, $\chi^{2}(\mathrm{df}=3, \mathrm{~N}=97)=25.79, P<.001$. The $R^{2}$ results indicate that $36 \%$ of the variance in OSA is accounted for by step 2 of the model. Classification statistics for each block of the regression are provided in Table 3. Most notably, addition of ISI scores to the model increased sensitivity by 0.19 , positive predictive value by 0.17 , and percentage of correctly classified cases by $5.2 \%$.

\section{Analyses of Insomnia Patterns by Sex}

Given previous findings regarding insomnia as an indicator of OSA in women, we analyzed the insomnia patterns by sex. Regardless of OSA diagnosis, ISI scores were higher for women compared with men $(8.7 \pm 6.3$ vs $6.4 \pm 4.7 ; P=.033)$. They also were higher for women with OSA compared with women without OSA $(13.6 \pm 7.4$ vs $7.1 \pm 5.0$; $P=.007)$. Among all subjects with a clinical diagnosis of OSA, ISI scores for women with OSA were higher than ISI scores for men with OSA (13.6 \pm

Table 3. Classification Statistics for the Logistic Regression Model for Prediction of Sleep Apnea With (Step 2) and Without (Step 1) Inclusion of Insomnia Symptoms

\begin{tabular}{lccccc}
\hline Logistic Regression & \% Correct & Sensitivity & Specificity & Positive Predictive Value & Negative Predictive Value \\
\hline Step $1^{*}$ & 80.4 & 0.29 & 0.95 & 0.60 & 0.83 \\
Step 2 & 85.6 & 0.48 & 0.96 & 0.77 & 0.87 \\
\hline
\end{tabular}

${ }^{*} \mathrm{BMI}$ and ESS.

${ }^{\dagger} \mathrm{BMI}, \mathrm{ESS}$, and ISI.

BMI, body mass index; ESS, Epworth Sleepiness Scale; ISI, Insomnia Severity Index. 
7.4 vs $9.6 \pm 5.0$ ). Although revealing a strong trend, this difference did not reach statistical significance $(P=.06)$.

Analyses of Insomnia Patterns by Age (Adults Age 18 to 54 Versus Older Adults Age $\geq 55$ )

Given previous findings that older adults with OSA may present with a primary complaint of insomnia, we analyzed age-related patterns within the ISI data. In the full sample ( $\mathrm{n}=45$ older adults; $\mathrm{n}=55$ adults), ISI scores were lower for older adults compared with adults $(6.4 \pm 5.4$ vs $8.7 \pm 5.9 ; P=.047)$. In the subsample of subjects with OSA $(\mathrm{n}=10$ older adults; $\mathrm{n}=13$ adults), ISI scores were lower for older adults compared with adults, but this difference was not significant $(10.7 \pm 6.3$ vs $13.1 \pm$ $7.1 ; P=.414)$. OSA patients had higher ISI scores than non-OSA patients regardless of age category.

\section{Discussion}

Insomnia symptoms add significant independent predictive value for OSA in this primary care sample. Inquiry regarding insomnia symptoms in the routine screening for OSA in primary care may improve clinical identification of OSA. Insomnia symptoms may be most relevant for prediction of OSA among women. This suggests that more attention should be focused on the possibility of OSA in women with a presenting complaint of insomnia.

ISI scores were predictive of OSA in this study. However, 2 previous studies found insomnia symptoms to be related to Apnea-Hypopnea Index or Respiratory Distress Index but concluded that insomnia symptoms did not provide sufficient independent predictive value for inclusion in the final screening model. ${ }^{14,39} \mathrm{We}$ propose 3 primary explanations for this discrepancy between our findings and those of previous studies.

First, our findings of increased sensitivity and positive predictive value associated with insomnia symptoms may represent a true difference in insomnia symptoms between an unselected primary care population and a sleep center population that has been prescreened for sleep disorders. This is consistent with the single previous study of insomnia as a predictor of OSA in primary care, which found that an insomnia complaint increased the probability of classification as high risk for OSA on the Berlin questionnaire (odds ratio, 2.7; 95\% CI, $1.5-4.9) .{ }^{37}$ Given the known variation in predictive characteristics of diagnostic tests between populations, this is a probable explanation. ${ }^{18}$

Second, sex differences in symptom presentation of OSA have been suggested as a possible cause of undiagnosed and misdiagnosed cases of OSA among women. ${ }^{32,34,46,47}$ Shepertycky and colleagues $^{34}$ found that, compared with men, women with OSA were more likely to have a main presenting symptom of insomnia (odds ratio, 4.2; 95\% CI, $1.54-14.26)$. Findings of Valipour and colleagues ${ }^{46}$ indicate women with OSA report more insomniatype symptoms than men with OSA. Consistent with these findings, ISI scores in our study differentiated men from women and women with OSA from women without OSA. Based on the above findings and the independent predictive utility of insomnia symptoms in the current study, we propose that inclusion of insomnia symptoms in the screening and evaluation of OSA may lead to less misdiagnosis of OSA in women.

Third, overnight PSG is the "gold standard" for diagnosis of OSA. Therefore, the primary limitation of this study is that the criterion for classification of OSA and non-OSA subjects was use of a structured clinical interview. In the absence of PSG data we are unable to comment on the utility of insomnia symptoms to discriminate OSA and nonOSA patients based on the Apnea-Hypopnea Index or Respiratory Distress Index. This difference in diagnostic procedure may partially or fully explain the discrepancy between the current results and those of prior investigations. Accordingly, the current results need to be replicated in a future investigation using PSG to establish the diagnosis of OSA.

Concerns regarding use of a structured interview as a surrogate for PSG may partially be ameliorated by the fact that the DSI does have moderate to high convergent validity with PSG-diagnosed OSA. ${ }^{44}$ Given the validity of the DSI, our findings of increased sensitivity and positive predictive value associated with inclusion of insomnia scores suggest that querying this symptom likely will help to identify correctly patients for PSG in a family medicine setting. The prevalence of OSA in our sample is $23 \%$, which is consistent with the estimated true prevalence of $15 \%$ to $22 \%$ in a primary care population recently reported by Mold and colleagues. ${ }^{2}$ Given the dependence of predictive values on prevalence rates, we believe the prevalence of OSA in 
our sample increases the validity of our predictive statistics.

Three additional limitations should be noted. First, the study was not designed to select a random sample or a sample representative of the larger primary care practice. In addition, despite instructions that all patients were eligible for participation, the recruiting procedures used may have produced a sample influenced by the biases of the recruiting physician or individual patients. Second, the sample size was relatively small and there were only 23 OSA subjects. Although this limits the strength and generalizability of the current findings, the sample size is appropriate for a preliminary and exploratory study. Third, although the current results support the candidacy of insomnia symptoms for inclusion in screening for OSA in primary care, use of the ISI in primary care is unrealistic. Accordingly, further investigation is required to specify a method of inquiry regarding insomnia symptoms that improves clinical identification of OSA and can be integrated realistically into the clinical practice of primary care medicine.

Regarding the relationship between insomnia and OSA in older adults, our findings did not support insomnia as a predictor of OSA in our subsample of older adults. In fact, our results suggest that the utility of insomnia for predicting OSA is not mediated by age.

\section{Conclusions}

Insomnia symptoms provide independent predictive value for identification of OSA in a primary care sample. The function of insomnia symptoms as a predictive variable for OSA may differ according to the population being evaluated. The predictive utility of insomnia seems to be most relevant for women. Inclusion of insomnia symptoms in the screening for OSA in primary care may improve clinical prediction of OSA, although the specific method of inclusion remains to be delineated.

We acknowledge and appreciate the assistance of Kurt Lesh, MD, and David C. Bird, MD, who recruited the subjects for this study and kindly allowed the execution of this study in their practice. We acknowledge the assistance of David Dean in the preparation of study data for analysis. We also acknowledge and appreciate the assistance of Kethera Fogler, who assisted greatly with statistical analyses.

\section{References}

1. Young T, Palta M, Dempsey J, Skatrud J, Weber S, Badr S. The occurrence of sleep-disordered breathing among middle aged adults. N Engl J Med 1993; 328:1230-5.

2. Mold J, Quattlebaum C, Schinnerer E, Boekman L, Orr $W$, Hollabaugh $\mathrm{K}$. Identification by primary care clinicians of patients with obstructive sleep apnea: a practice-based research network (PBRN) study. J Am Board Fam Med 2011;24:138-45.

3. Caples S, Kara T, Somers V. Cardiopulmonary consequences of obstructive sleep apnea. Semin Respir Crit Care Med 2005;26:25-32.

4. Mehra R, Benjamin E, Shahar E, et al. Association of nocturnal arrhythmias with sleep-disordered breathing: the Sleep Heart Health Study. Am J Respir Crit Care Med 2006;173:910-6.

5. Arzt M, Young T, Finn L, Skatrud J, Bradley T. Association of sleep-disordered breathing and the occurrence of stroke. Am J Respir Crit Care Med 2005;172:1447-51.

6. Young T, Peppard P, Palta M, et al. Population-based study of sleep-disordered breathing as a risk factor for hypertension. Arch Intern Med 1997;157:1746-52.

7. Peppard P, Young T, Palta M, Skatrud J. Prospective study of the association between sleep-disordered breathing and hypertension. N Engl J Med 2000; 342:1378-84.

8. Punjabi N, Sorkin J, Katzel L, Goldberg A, Schwartz A, Smith P. Sleep-disordered breathing and insulin resistance in middle-aged and overweight men. Am J Respir Crit Care Med 2002;165:677-82.

9. Rakel R. Clinical and societal consequences of obstructive sleep apnea and excessive daytime sleepiness. Postgrad Med 2009;121:86-95.

10. Deldin P, Phillips L, Thomas R. A preliminary study of sleep-disordered breathing in major depressive disorder. Sleep Med 2006;7:131-9.

11. Epstein L, Kristo D, Strollo P, et al. Clinical guideline for the evaluation, management, and long-term care of obstructive sleep apnea in adults. J Clin Sleep Med 2009;5:263-76.

12. Collop N, Anderson W, Boehlecke B, et al. Clinical guidelines for the use of unattended portable monitors in the diagnosis of obstructive sleep apnea in adult patients. J Clin Sleep Med 2007;3:737-47.

13. Kushida C, Littner M, Morgenthaler T, et al. Practice parameters for the indications for polysomnography and related procedures: an update for 2005 . Sleep 2005;28:499-521.

14. Rodsutti J, Hensley M, Thakkinstian A, D'Este C, Attia J. A clinical decision rule to prioritize polysomnography patients with suspected sleep apnea. Sleep 2004;27:694-9.

15. Pouliot Z, Peters M, Neufeld H, Kryger M. Using self-reported questionnaire data to prioritize OSA patients for polysomnography. Sleep 1997;20:232-6. 
16. McNicholas W. Diagnosis of obstructive sleep apnea in adults. Proc Am Thorac Soc 2008;5:154-60.

17. Kapuniai L, Andrew D, Crowell D, Pearce J. Identifying sleep apnea from self-reports. Sleep 1988;11: 430-6.

18. Maislin G, Pack A, Kribbs N, et al. A survey screen for prediction of apnea. Sleep 1995;18:158-66.

19. Flemons $W, M c N i c h o l a s ~ W$. Clinical prediction of the sleep apnea syndrome. Sleep Med Rev 1997;1:19-32.

20. Harding S. Prediction formulas for sleep-disordered breathing. Curr Opin Pulm Med 2001;7:381-5.

21. Rowley J, Aboussouan 1, Badr M. The use of clinical prediction formulas in the evaluation of obstructive sleep apnea. Sleep 2000;23:929-38.

22. Viner S, Szalai J, Hoffstein V. Are history and physical examination a good screening test for sleep apnea. Ann Intern Med 1991;115:356-9.

23. Haraldson P, Carenfelt C, Knutsson E, Persson H, Rinder J. Preliminary report: validity of symptom analysis and daytime polysomnography in diagnosis of sleep apnea. Sleep 1992;15:261-3.

24. Hoffstein V, Szalai J. Predictive value of clinical features in diagnosing obstructive sleep apnea. Sleep 1993;16:118-22.

25. Flemons $W$, Whitelaw W, Brant R, Remmers J. Likelihood ratios for a sleep apnea clinical prediction rule. Am J Respir Crit Care Med 1994;150:1279-85.

26. Crocker B, Olson L, Saunders N, et al. Estimation of the probability of disturbed breathing during sleep before a sleep study. Am Rev Respir Dis 1990;142:12-8.

27. Netzer N, Stoohs R, Netzer C, Clark K, Strohl K. Using the Berlin questionnaire to identify patients at risk for the sleep apnea syndrome. Ann Intern Med 1999;131:485-91.

28. Chai-Coetzer CL, Antic NA, Rowland LS. A simplified model of screening questionnaire and home monitoring for obstructive sleep apnoea in primary care. Thorax 2011:66;213-9.

29. Tishler P, Larkin E, Schluchter M, Redline S. Incidence of sleep-disordered breathing in an urban adult population: the relative importance of risk factors in the development of sleep-disordered breathing. JAMA 2003;289:2230-7.

30. Pillar G, Shehadeh N. Abdominal fat and sleep apnea: the chicken or the egg? Diabetes Care 2008; 31(Suppl 2):S303-9.

31. Redline S, Kump K, Tishler P, Browner I, Ferrette $\mathrm{V}$. Gender differences in sleep disordered breathing in a community based sample. Am J Respir Crit Care Med 1994;149:722-6.

32. Kapismalis F, Kryger M. Gender and obstructive sleep apnea syndrome. Part 1: Clinical features. Sleep 2002;25:412-9.
33. Baldwin C, Kapur V, Holberg C, Rosen C, Nieto F, Sleep Heart Health Study Group. Associations between gender and measures of daytime somnolence in the sleep heart health study. Sleep 2004;27:305-11.

34. Shepertycky M, Banno K, Kryger M. Differences between men and women in the clinical presentation of patients diagnosed with obstructive sleep apnea syndrome. Sleep 2005;28:309-14.

35. Lichstein KL, Riedel BW, Lester KW, Aguillard RN. Occult sleep apnea in a recruited sample of older adults with insomnia. J Consult Clin Psychol 1999;67(3):405-10.

36. Bouscoulet LT, Vazquez-Garcia JC, Muino A. Prevalence of sleep related symptoms in four Latin American cities. J Clin Sleep Med 2008:4;579-85.

37. Grover M, Mookadam M, Armas D. Identifying patients at risk for obstructive sleep apnea in a primary care practice. J Am Board Fam Med 2011:24;152-60.

38. Tsai W, Remmers J, Brant R, Flemons W, Davies J, Macarthur C. Decision rule for diagnostic testing in obstructive sleep apnea. Am J Crit Care Med 2003; 167:1427-32.

39. Kump K, Whalen C, Tishler P, et al. Assessment of the validity and utility of a sleep-symptom questionnaire. Am J Crit Care Med 1994;150:735-41.

40. Scharf S, Garshick E, Brown R, Tishler P, Tosteson $\mathrm{T}$, McCarley R. Screening for subclinical sleep-disordered breathing. Sleep 1990;13:344-53.

41. Morin C. Insomnia: psychological assessment and management. New York: Guilford Press; 1993.

42. Bastien CH, Vallieres A, Morin C. Validation of the insomnia severity index as an outcome measure for insomnia research. Sleep Med 2001;2:297-307.

43. Johns M. A new method for measuring daytime sleepiness: the Epworth Sleepiness Scale. Sleep 1991;14:540-5.

44. Edinger J, Wyatt J, Stepanski E. Testing the reliability and validity of DSM-IV-TR and ICSD-2 insomnia diagnoses. Arch Gen Psychiatry 2011; 68: 992-1002.

45. Agresti A. An introduction to categorical data analysis. 2nd ed. New York: John Wiley \& Sons; 2007.

46. Valipour A, Lothaler H, Rauscher H, Zwick H, Burghuber O, Lavie P. Gender-related differences in symptoms of patients with suspected breathing disorders in sleep: a clinical population study using the sleep disorders questionnaire. Sleep 2007;30: 312-9.

47. Young T, Hutton R, Finn L, Badr S, Palta M. The gender bias in sleep apnea diagnosis: are women missed because they have different symptoms? Arch Intern Med 1996;156:2445-51. 